\title{
Role and Limitations of Laparoscopic Liver Resection of Colorectal Metastases
}

\author{
Tom Mala $^{a}$ Bjørn Edwin ${ }^{b}$

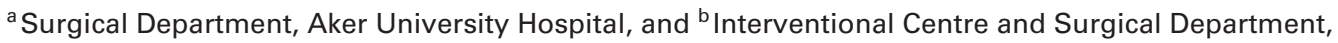 \\ Rikshospitalet University Hospital, Oslo, Norway
}

\section{Key Words}

Laparoscopy $\cdot$ Hepatectomy $\cdot$ Colorectal liver

metastases $\cdot$ Liver resection $\cdot$ Metastases

\begin{abstract}
Background: The current experience of laparoscopic liver resection is reviewed focusing on the role and limitations of resection of colorectal metastases. Surgical technique, outcome, and the main controversies regarding the procedures are described. Methods: Current literature on laparoscopic liver resection is reviewed based on reports identified following a specified PubMed search. Results: Available evidence indicates that laparoscopic liver resection can be made safely in selected patients with comparable duration of surgery, blood loss, tumour clearance, and mortality to that of open resection. Tumours localised peripherally in the left lateral segments of the liver or in segments IV-VI seem to be best suited for laparoscopic resection. The laparoscopic approach may be beneficial to the patients as compared to conventional resection but randomised trials are pending. Laparoscopic resection of colorectal liver metastases is described in a small number of patients only. The longterm outcome following such resections is not ade-
\end{abstract}

quately documented. Conclusions: Laparoscopic liver resection is a promising technique with a comparable short-term outcome to that of open procedures but with the potential advantages of minimal invasive treatment. The technique should be further evaluated in properly designed trials. Laparoscopic resection of colorectal liver metastases should not be performed on a regular basis until long-term results are defined.

Copyright $(2005$ S. Karger AG, Basel

Laparoscopy is used for an increasing number of indications. Liver resection is one of the last frontiers of the technique to be expanded. The feasibility and safety of laparoscopic liver resection have been indicated in several reports $[1-18]$. The procedures are technically demanding and experience in conventional hepatobiliary surgery and advanced laparoscopy is required. The main reason for advocating laparoscopy is that the approach is less invasive than laparotomy and thus believed to be beneficial to the patients.

The most frequent liver neoplasms considered for open resection are metastases from colorectal cancer and hepatocellular carcinoma. Benign tumours rarely require surgical intervention.

\section{KARGER}

Fax +4161306 1234 E-Mail karger@karger.ch www.karger.com 
The 5-year survival rates following conventional resection of colorectal liver metastases are reported between 25 and 40\% [19-21]. Studies indicate that repeated treatment of metastatic liver recurrences may be beneficial to some patients $[22,23]$. Tumour ablation has been increasingly used for patients with non-resectable colorectal liver metastases alone or as combined procedures with resection of resectable lesions [24]. Thus, a more aggressive approach to patients with colorectal liver metastases is reported in recent series. In this setting, the development of less invasive procedures seems reasonable.

The present report reviews the current experience in laparoscopic liver resection focusing on the role and limitations of such procedures for patients with colorectal metastases.

\section{Techniques of Laparoscopic Liver Resection}

The techniques of laparoscopic liver resection have been described in several reports and a summary is presented only $[1,2,13,24,25]$. $\mathrm{CO}_{2}$ pneumoperitoneum or gasless laparoscopy may be applied [26]. The rationale for using the gasless technique is to prevent potential gas embolism during pneumoperitoneum. During gasless laparoscopy, intra-abdominal space for surgical manoeuvring is established by abdominal wall suspension techniques. Some have used gasless laparoscopy for major resections and pneumoperitoneum for minor resections [2]. We have used low-pressure $\mathrm{CO}_{2}$ pneumoperitoneum in an attempt to reduce the risk of gas embolism [25].

The totally laparoscopic approach to liver resection should be differentiated from the hand-assisted approach [27]. By the latter technique a port is made where the surgeon can place one hand to assist resection while maintaining pneumoperitoneum. The intra-abdominal hand can be used for manual retraction, assessment of resection margins during resection and may facilitate control of bleeding. The hand-assisted approach may be especially beneficial during large resections of the liver.

We have typically used three to five trocars sized 12 and $11 \mathrm{~mm}$, and a $30^{\circ}$ laparoscope [24, 25]. For tumours located in the right lateral part of the liver the patients are placed in a lateral position with the right side elevated $30-45^{\circ}$. A diagnostic and staging laparoscopy is performed and the liver is examined using laparoscopic ultrasonography with a high-frequency probe $(7.5 \mathrm{MHz})$ with Doppler function. A thoracoscopic approach has recently been described for the resection of lesions located in the postero-superior part of the liver [28].

Laparoscopic Liver Resection
Several types of resections may be made. The two principle types are the local non-anatomic (wedge) resections and the anatomic resections including single or multiple segmentectomies such as hemihepatectomies [2, 12, 17].

The area to be resected is marked on the liver surface by electrocautery. The resections are started using an ultrasonic scalpel that seals small vessels and bile ducts. Deeper within the liver the ultrasound surgical aspirator (CUSA/Selector) is used to fracture and evacuate liver tissue. Minor vessels and bile ducts remain preserved and can be divided using the ultrasonic scalpel, diathermy, or clips. Larger vessels are divided using laparoscopic stapling devices or clips. Recently, we have applied LigaSure (Boulder, Colo., USA) to divide vessels and a laparoscopic SonoDoppler probe (Sintef Helse/Mision, Trondheim, Norway) to aid detection of blood vessels located close to the target tumour. Other instruments applied during liver transection include the water jet dissector, different types of lasers and stapling devices.

The resections are guided by repeated ultrasonographic assessment of tumour location to ensure adequate tumour clearance. This is particularly important for nonanatomic resections as the target tumour may be located close to the planned resection route. Care is taken not to manipulate the tumour tissue. On the resection surface, suction is performed to allow adequate visualisation during resection.

During resection, hepatic vascular inflow occlusion by temporary clamping of the hepatoduodenal ligament is applied by many to reduce intraoperative bleeding. Another means of reducing intraoperative hemorrhage is to reduce the central venous pressure. This should be done carefully as the risk of gas embolism may increase since the intra-abdominal pressure increases relative to the pressure in the hepatic veins.

The resected specimen is removed in one piece through an enlarged trocar port (minilaparotomy) or through the hand port for hand-assisted procedures. For benign lesions, some have used specimen-crushing techniques before retraction from the abdominal cavity. We have mostly extracted specimens through a small midline incision enlarging to the umbilical trocar port. Some routinely place an abdominal drain close to the resection surface although this may not always be necessary [29]. Fibrin glues have been used to seal the resection surface [1, 17].

In malignancy, special attention is paid to specimen removal and to the use of the trocars. Gas evacuation should be done with the trocars in place and care should be taken to avoid gas leakage along the trocars during 
Table 1. Reports of laparoscopic liver resections including 15 procedures or more as identified from PubMed (see text for search criteria). Studies including patients described in other reports are italicised. Two multicentre studies $[8,11]$ may include some patients presented in other studies

\begin{tabular}{|c|c|c|c|c|c|c|c|c|}
\hline Group (first author) & $\begin{array}{l}\text { Proce- } \\
\text { dures }\end{array}$ & $\begin{array}{l}\text { Benign/ } \\
\text { malignant }\end{array}$ & $\begin{array}{l}\text { Colorectal } \\
\text { cancer, } \%\end{array}$ & $\begin{array}{l}\text { Duration } \\
\text { of surgery } \\
\text { min }\end{array}$ & $\begin{array}{l}\text { Rate of } \\
\text { conversion } \\
\%\end{array}$ & $\begin{array}{l}\text { Blood loss } \\
\mathrm{ml}\end{array}$ & $\begin{array}{l}\text { Morta- } \\
\text { lity, } \%\end{array}$ & $\begin{array}{l}\text { Hospital } \\
\text { stay, days }\end{array}$ \\
\hline Rau, 1998 [1] & 17 & Mixed & 6 & 183 & 6 & 457 & 0 & 7.8 \\
\hline Huscher, 1998 [2] & 38 & Mixed & $<44$ & 189 & 5 & 380 & $3^{4}$ & 10 \\
\hline Huscher, 1997 [3] & 20 & Mixed & 15 & 193 & 0 & 397 & 5 & $11^{2}$ \\
\hline Cherqui, 2000 [4] & 30 & Mixed & 0 & 214 & 7 & 300 & 0 & 9.6 \\
\hline Lesurtel, 2003 [5] & 18 & Mixed & 6 & 202 & 11 & 236 & 0 & 8 \\
\hline Descottes, 2000 [6] & 16 & Mixed & 6 & 232 & 6 & - & 0 & 5.2 \\
\hline Shimada, 2001 [7] & 17 & Malignant & 0 & $325^{2}$ & 0 & $400^{2}$ & 0 & 12 \\
\hline Gigot, 2002 [8] & 37 & Malignant & 32 & - & 13.5 & - & 0 & 7 \\
\hline Farges, 2002 [9] & 21 & Benign & 0 & 177 & 0 & 218 & 0 & 5.1 \\
\hline Morino, 2003 [10] & 30 & Mixed & 17 & 148 & 0 & 320 & 0 & 6.4 \\
\hline Descottes, 2003 [11] & 87 & Benign & 0 & - & 10 & - & 0 & 5 \\
\hline Buell, 2005 [12] & 100 & Mixed & $<35$ & 132 & 0 & - & $1^{4}$ & 3 \\
\hline Buell, 2004 [13] & 17 & Mixed & 6 & 168 & 0 & 288 & 6 & 2.9 \\
\hline Mala, 2005 [14] & 53 & Mixed & 79 & $187^{2}$ & 6 & $700^{2}$ & 0 & $3.5^{2}$ \\
\hline Kaneko, 2005 [15] & 30 & Malignant & 0 & 182 & 3 & $350^{3}$ & 0 & 14.9 \\
\hline Tagaki, $2002[16]^{1}$ & 19 & Mixed & $<11$ & - & 0 & - & 0 & - \\
\hline Dulucq, 2005 [17] & 32 & Mixed & 35 & 115 & 9 & 210 & 0 & 11 \\
\hline \multicolumn{9}{|l|}{$-=$ Not specified } \\
\hline
\end{tabular}

laparoscopy. Some employ extraction site protection using plastic sheets.

We have applied total intravenous anaesthesia in most of our patients during surgery. At the beginning of the procedure, local anaesthetics are injected at the trocar port sites. Postoperative analgesia typically consists of a combination of a NSAID and intravenous paracetamol. On the first postoperative day, ketobemidon is given if required. Later, oral paracetamol and codeine are used [25].

\section{Current Clinical Experience with Laparoscopic Liver Resection}

\section{Reports of Feasibility and Safety}

The first laparoscopic non-anatomic and anatomic liver resections were reported in 1991 and 1996, respectively $[30,31]$. For the present review, series published in English between 1991 and May 30, 2005 were identified from a PubMed search by screening all report titles or abstracts identified following a specified search and selecting those related to the theme of interest. Studies describing predominantly or exclusively hepatic cyst resections or deroofing were excluded. Reports including 15 patients or more were included to compensate for an initial learning curve and to reduce the substantial number of case reports identified. The key words used for the searches were 'laparoscopy and liver resection', 'laparoscopy and hepatectomy', and 'liver resection and minimal invasive surgery'. Reviews were screened for additional references [32-37]. Studies that compared laparoscopic to open liver resection were included regardless of the number of patients treated.

The results of the PubMed search are listed in tables $1-3$. Although the experience is limited, more than 500 procedures were identified. Some procedures may have been calculated twice due to the two multicentre studies performed. No randomised studies between open and laparoscopic procedures were found. In most reports, different types of tumours were included. 
Table 2. Resection margins following resection of malignant liver tumours as extracted from reports cited in table 1 and 3

\begin{tabular}{|c|c|c|c|c|c|}
\hline Group (first author) & $\begin{array}{l}\text { Eligible } \\
\text { specimens }\end{array}$ & Type of lesions & $\begin{array}{l}\text { Resection } \\
\text { margin } \\
<1 \mathrm{~cm}, \%\end{array}$ & $\begin{array}{l}\text { Tumour tissue } \\
\text { in resection } \\
\text { margin, } \%\end{array}$ & $\begin{array}{l}\text { Statistically } \\
\text { different from } \\
\text { open group }\end{array}$ \\
\hline Rau, 1998 [1] & 1 & Colorectal & 0 & 0 & - \\
\hline Shimada, 2001 [7] & 17 & Hepatocellular & $41^{2}$ & - & No \\
\hline Mala, 2002 [25] & 21 & Colorectal & 29 & 5 & No \\
\hline Gigot, 2002 [8] & 25 & Mixed & 28 & 4 & - \\
\hline Laurent, 2003 [18] & 13 & Primary & $23^{2}$ & $8^{3}$ & No \\
\hline Morino, 2003 [10] & 30 & Mixed & 43 & 0 & No \\
\hline Lesurtel, 2003 [5] & 6 & Mixed & 17 & 0 & - \\
\hline Buell, 2004 [13] & 5 & Mixed & 0 & 0 & - \\
\hline Mala, 2005 [14] & 52 & Mixed $^{1}$ & - & 6 & - \\
\hline Dulucq, 2005 [17] & 18 & Mixed & - & 6 & - \\
\hline
\end{tabular}

Table 3. Short-term results following open and laparoscopic liver resection. None of the studies are randomised. Values are presented as mean for minutes ( $\mathrm{min})$, millilitres $(\mathrm{ml})$, and days if not stated otherwise

\begin{tabular}{|c|c|c|c|c|c|c|}
\hline Group (first author) & $\begin{array}{l}\text { Patients } \\
\text { open/lap }\end{array}$ & $\begin{array}{l}\text { Operative } \\
\text { time (min) } \\
\text { open/lap }\end{array}$ & $\begin{array}{l}\text { Mortality } \\
\text { open/lap }\end{array}$ & $\begin{array}{l}\text { Blood loss } \\
(\mathrm{ml}) \\
\text { open/ lap }\end{array}$ & $\begin{array}{l}\text { Conversion } \\
\text { to open } \\
\text { resection, \% }\end{array}$ & $\begin{array}{l}\text { Hospital stay } \\
\text { (days) } \\
\text { open/lap }\end{array}$ \\
\hline Rau, 1998 [1] & $34(17 / 17)$ & $128 / 183^{1}$ & 0 & $555 / 457$ & 6 & $11.6 / 7.8^{1}$ \\
\hline Shimada, 2001 [7] & $55(38 / 17)$ & $280 / 325^{2}$ & 0 & $800 / 400^{2}$ & 0 & $22 / 12^{1}$ \\
\hline Mala, 2002 [25] & $27(14 / 13)$ & $185 / 187$ & 0 & $500 / 600$ & 0 & $8.5 / 4^{1}$ \\
\hline Farges, 2002 [9] & $42(21 / 21)$ & $156 / 177$ & 0 & $285 / 218$ & 0 & $6.5 / 5.1^{1}$ \\
\hline Morino, 2003 [10] & $60(30 / 30)$ & $142 / 148$ & 0 & $479 / 320^{1}$ & 0 & $8.7 / 6.4^{1}$ \\
\hline Lesurtel, 2003 [5] & $38(20 / 18)$ & $145 / 202$ & 0 & $429 / 236^{1}$ & 11 & $10 / 8$ \\
\hline Kaneko, 2005 [15] & $58(28 / 30)$ & $210 / 182$ & 0 & $505 / 350$ & 3 & $21.6 / 14.9^{1}$ \\
\hline Laurent, 2003 [18] & $27(14 / 13)$ & $182 / 267^{1}$ & $2 / 0$ & $720 / 620$ & 15 & $17.3 / 15.3$ \\
\hline
\end{tabular}

Resection during laparotomy (open) and laparoscopy (lap).

${ }^{1}$ Statistically significant difference, i.e. $\mathrm{p}<0.05$.

2 Median.

According to recent reviews, more than 700 laparoscopic liver procedures have been reported since 1991 $[32,33]$, many as case reports or small series. Close to $30 \%$ of these procedures have been performed for varying types of malignant lesions [33]. The most common interventions described in these reviews have been laparoscopic fenestration and deroofing of liver cysts [33]. Nonanatomic resections of peripheral and superficial tumours have been the most frequent resections performed but anatomic resections are also done, particularly left lateral segmentectomies (i.e. Couinaud segments II and III). Formal hemihepatectomies have been performed more rarely $[32,33]$.

The rate of conversion to open liver resection is reported between 0 and 14\% (table 1). The main cause is intraoperative bleeding $[32,33]$. Another cause of par- 
ticular relevance for colorectal metastases is peritoneal adhesions due to previous abdominal surgery. Most of these patients have peritoneal adhesions following surgery of the primary tumour, although to a varying degree. The magnitude of this problem is yet to be defined.

Based on reports presented in table 2, tumour clearance following laparoscopic liver resection seems to be comparable to that following open resection. Studies of open resection of colorectal liver metastases have shown that the incidence of involved resection margins is approximately $10 \%$ [19-21]. These results, however, should be improved for both conventional and laparoscopic procedures. Patient selection is an important variable in the evaluation of adequacy of tumour clearance when comparing different techniques of tumour resection.

The mortality following laparoscopic liver resection is low and comparable to that of open liver resection which in most centres is $<5 \%$ (table 1 ). The mortality following laparoscopic liver resection reported in the review by Gagner and Rogula [33] was 0.3\% (2 patients) which seems to concur with our findings of 2 deaths in more than 500 patients (table 1), i.e. $<0.4 \%$. The cause of death in these 2 patients was hepatic failure $[2,12]$.

The reports in tables 1-3 indicate that laparoscopic liver resection can be considered a safe and feasible procedure for selected patients in regard to short-term outcome. The evidence for these findings, however, should be enforced.

\section{Short-Term Efficacy of Laparoscopic as Compared to Conventional Liver Resection}

Several advantages have been suggested for the laparoscopic approach to liver resection; reduced surgical trauma and inflammatory stress response, less patient discomfort, facilitated rehabilitation, and reduced duration of hospital stay. Laparoscopy also offers improved cosmetics as compared to the often large subcostal incisions made during open procedures. Additional advantages include abdominal wall saving and a suggested reduced formation of peritoneal adhesions which may ease the performance of repeated procedures. For patients with portal hypertension, preservation of abdominal wall venous collaterals can be beneficial.

Although promising and convincing to many, the effects of laparoscopic as compared to open liver resection have not been extensively documented. Evidence comes from small non-randomised studies only (table 3 ). These studies, however, show that the procedure can be performed safe and successfully with acceptable complica- tion rates. They also indicate that the laparoscopic approach may be beneficial to the patients: five of seven comparative studies indicate shorter postoperative hospital stay for laparoscopic procedures (table 3). In our study of 53 procedures the median number of days in need of postoperative analgesia stronger than paracetamol and codeine was 1 day (range 0-11) [14]. Intraoperative blood loss seems to be comparable to that of conventional surgery. In fact a reduced blood loss following laparoscopy is indicated. However, the current evidence for the potential beneficial effects of laparoscopic liver resection needs to be substantiated in properly designed randomised trials.

\section{Controversies in Laparoscopic Liver Resections}

The main controversies in laparoscopic liver resection have been the risk of compromising oncologic outcome following resection, gas embolism, and that the procedures represent hazardous surgery with potential bleeding difficult to handle and prolonged duration of surgery.

For laparoscopy to be considered an alternative to conventional liver surgery in malignant disease, long-term oncologic outcome must not be jeopardized. There have been two main focuses on the potential deleterious effects of the laparoscopic approach in intra-abdominal malignancy: the risk of port-site and intra-abdominal tumour seeding from tumour manipulation and pneumoperitoneum, and the risk of inadequate tumour resection.

The fear of port-site metastases was induced by the high incidence of such metastases from the early experience in laparoscopy for intra-abdominal malignancy [38]. However, recent reports indicate a similar risk for wound metastases following open and laparoscopic surgery, i.e. $<1 \%$, if conventional oncologic principles are used during resection $[39,40]$. Pneumoperitoneum has been suggested to promote tumour implantation and seeding, but these theories have not been confirmed in clinical studies.

There is evidence that surgical stress impairs immunity [41]. This may influence the rate of septic complications and tumour metastasis formation postoperatively. The immune dysfunction has been claimed to be reduced following laparoscopic as compared to conventional surgery [42]. An early randomised study indicated improved outcome for some stages of colorectal cancer following laparoscopic surgery. Reduced surgical stress was dis- 
cussed as a possible explanation [43]. Potential differences in immunologic response following open and laparoscopic resection of colorectal tumours and clinical relevance thereof, however, are not established.

The issue of inadequate tumour clearance during laparoscopy has been discussed in the previous section. Although evidence indicates that the adequacy of tumour resection is comparable to that of open procedures these findings need to be confirmed in adequate designed trials (table 2).

Gas embolism has been feared during laparoscopic liver resection due to dissection close to low-pressure veins during pneumoperitoneum. The incidence in a recent review article of more than 700 laparoscopic interventions on the liver was $0.3 \%$ [33]. Gas embolism during laparoscopic liver resection was not described in the reports shown in table 1 including more than 500 patients. This is probably due to the high solubility of $\mathrm{CO}_{2}$ in blood. However, intravascular gas bobbles have been shown following different types of laparoscopy, although the significance of these is unknown [44]. Attention should be paid to reduce the risk of gas embolism.

There has also been concern of potential negative hemodynamic effects of the pneumoperitoneum. One study that evaluated the mean arterial pressure, systemic vascular resistance and cardiac index during vascular clamping of the hepatoduodenal ligament in open and laparoscopic liver resection, however, found no differences between the groups. The patients, who all had normal cardiac function, tolerated the procedures well. The study may not have been adequately sized to show potential differences and further studies are required [45].

As shown in tables 1 and 3, the duration of surgery may be somewhat longer for laparoscopic procedures than for open procedures. This may be due to a learning curve. However, the differences were not significant in several of the reports (table 3). The laparoscopic procedures do not seem to be more hazardous as compared to open procedures based on the mortality rate, intraoperative blood loss, and hospital stay from reports in tables 1 and 3. Thus, from available evidence the short-term outcome of laparoscopic procedures in selected patients cannot be claimed to be more hazardous than the open procedures.

\section{Role and Limitations of Laparoscopic Liver Resection of Colorectal Metastases}

\section{Role}

The role of laparoscopy in colorectal malignancy has changed over the years. Studies are currently evaluating laparoscopy as treatment for primary colorectal cancer [46]. Laparoscopic staging of colorectal metastatic disease is also used in selected patients prior to open liver resection. A preoperative score has been developed to define patients that may profit from such diagnostic procedures [47].

Laparoscopic resection of colorectal liver metastases is less extensively documented (tables 1,3 ). Repeated resections of liver recurrences may be beneficial to some of these patients and tumour ablation has become a treatment option for non-resectable tumours [22, 23]. Several techniques exist although radiofrequency ablation is most extensively documented [24, 48, 49]. Laparoscopic techniques may thus be particularly beneficial to patients with colorectal liver metastases as repetitive trauma may be reduced and may facilitate a multimodal approach to these patients [24]. Such repeated and combined treatments can offer survival benefits to selected patients but need to be further evaluated.

The reduced trauma and the potential advantages of laparoscopy support further evaluation and development of laparoscopic liver resection. Conventional resection represents a large trauma to the patients who may be at high age with an increased risk of complications due to co-morbidity. However, the risk of having to convert to laparotomy should always be considered in patients found eligible to laparoscopic surgery.

Adequate preoperative evaluation of tumour location is necessary. Attention should be paid to large vessels situated close to tumours as these may cause severe bleeding - particularly during non-anatomic resections. It has been recommended that liver lesions deemed eligible for laparoscopic resection should be reasonable small as large tumours can be difficult to mobilise and may have a higher risk of bleeding due to dangerous vascular supply [4]. Large and deeply situated tumours requiring major resections are not extensively documented and may have higher complication rates.

In our experience, tumours located in all eight liver segments except segment I have been resected [14]. Nonanatomic resections in both liver lobes and anatomic resections in the left lobe, i.e. left lateral segmentectomies, have been performed. Patients most suitable for laparoscopic liver resection have small localised tumours pe- 
ripherally located in the left lateral segments of the liver or in segments IV-VI $[8,11,18,33]$. Resection of lesions in the posterior and the superior part of the right liver lobe is technically demanding and is recommended to be approached with caution [10]. Tumours located close to the cavohepatic junction and the porta hepatis are usually resected through laparotomy.

A study indicates that anatomic segmental resection is superior to wedge resection as an oncologic procedure for colorectal liver metastasis due to improved tumour clearance and survival [50]. This finding needs to be further evaluated but may affect the type of resections that should be made for colorectal metastases.

Similar oncologic surgical principles should be applied in laparoscopic as in open resection of liver malignancies, i.e. radical tumour resection with preferentially $1-\mathrm{cm}$ free surgical margin and minimal tumour manipulation [51]. However, evidence indicates that a predicted margin $<1 \mathrm{~cm}$ should not be considered a contraindication to resection as the width of the clearance margin may not affect survival provided the resection is complete and there is no tumour infiltration within the margin [52].

\section{Limitations}

Importantly, tables 1 and 3 show that experience in laparoscopic liver resection for colorectal cancer is sparse and no large series exist. None of the reports have adequate documentation of long-term results following surgery. Laparoscopic liver resection is thus not an established treatment for colorectal metastases and further evaluation should be awaited before this procedure is performed on a regular basis.

The introduction of less invasive surgery should not extend the indications or change current protocols for treatment of colorectal metastases without the appropriate evidence for doing so. Similar oncologic contraindications as for open surgery apply for laparoscopic procedures. These include extrahepatic metastatic disease perhaps with the exception of pulmonary metastases in some patients [53]. Palliative resection of tumours, i.e. resection of only parts or some of established metastases, should not be done except in specially designed trials.

Peritoneal adherences following previous intra-abdominal infections and/or surgery may prevent adequate mobilisation of the liver and tumour resection. In our series of 53 laparoscopic procedures, 2 patients (4\%) had to be converted to open resection due to peritoneal adhesions [14]. Taking down peritoneal adhe- sions can be time consuming. Patients with previous peritoneal infections may thus be less suited for this approach.

Laparoscopic liver resection requires experience in conventional hepatobiliary surgery and advanced laparoscopic skills. Access to adequate technology is necessary. The use of this technique should thus probably be restricted to special centres with the required competence.

\section{Conclusions}

Available evidence indicates that the short-term safety, duration of surgery, and tumour clearance of laparoscopic liver resection in selected patients is comparable to that of open resection. It is also indicated that the laparoscopic approach may be beneficial to the patients. Currently, tumours localised peripherally in the left lateral segments of the liver or in segments IV-VI seem to be best suited for this approach. Laparoscopic resection of colorectal liver metastases has not been adequately evaluated and long-term results should be awaited before this treatment is performed on a regular basis. Introduction of minimally invasive surgery should not alter established treatment protocols for resection of colorectal liver metastases without the appropriate evidence for doing so. 


\section{References}

-1 Rau HG, Buttler E, Meyer G, Schardey HM, Schildberg FW: Laparoscopic liver resection compared with conventional partial hepatectomy - a prospective analysis. Hepatogastroenterology 1998;45:2333-2338.

-2 Huscher CG, Lirici MM, Chiodini S: Laparoscopic liver resections. Semin Laparosc Surg 1998;5:204-210.

-3 Huscher CG, Lirici MM, Chiodini S, Recher A: Current position of advanced laparoscopic surgery of the liver. J R Coll Surg Edinb 1997; 42:219-225.

4 Cherqui D, Husson E, Hammoud R, Malassagne B, Stephan F, Bensaid S, Rotmann N, Fagniez PL: Laparoscopic liver resections: a feasibility study in 30 patients. Ann Surg 2000;232: 753-762.

5 Lesurtel M, Cherqui D, Laurent A, Tayar C, Fagniez PL: Laparoscopic versus open liver resection: a case-control study. J Am Coll Surg 2003; 196:236-242.

-6 Descottes B, Lachachi F, Sodji M, Valleix D, Durand-Fontanier S, Pech de Laclause B, Grosseau D: Early experience with laparoscopic approach for solid liver tumors: initial 16 cases. Ann Surg 2000;232:641-645.

7 Shimada M, Hashizume M, Maehara S, Tsujita E, Rikimaru T, Yamashita Y, Tanaka S, Adachi E, Sugimachi K: Laparoscopic hepatectomy for hepatocellular carcinoma. Surg Endosc 2001; 15:541-544.

-8 Gigot JF, Glineur D, Santiago Azagra J, Goergen M, Ceuterick M, Morino M, Etienne J, Marescaux J, Mutter D, van Krunckelsven L, Descottes B, Valleix D, Lachachi F, Bertrand C, Mansvelt B, Hubens G, Saey JP, Schockmel R, Hepatobiliary and Pancreatic Section of the Royal Belgian Society of Surgery and the Belgian Group for Endoscopic Surgery: Laparoscopic liver resection for malignant liver tumors: preliminary results of a multicenter European study. Ann Surg 2002;236:90-97.

-9 Farges O, Jagot P, Kirstetter P, Marty J, Belghiti J: Prospective assessment of the safety of laparoscopic liver resections. J Hepatobiliary Pancreat Surg 2002;9:242-248.

10 Morino M, Morra I, Rosso E, Miglietta C, Garrone C: Laparoscopic vs. open hepatic resection. Surg Endosc 2003;17:1914-1918.

-11 Descottes B, Glineur D, Lachachi F, Valleix D, Paineau J, Hamy A, Morino M, Bismuth H, Castaing D, Savier E, Honore P, Detry O, Legrand M, Azagra JS, Goergen M, Ceuterick M, Marescaux J, Mutter D, de Hemptinne B, Troisi R, Weerts J, Dallemagne B, Jehaes C, Gelin M, Donckier V, Aerts R, Topal B, Bertrand C, Mansvelt B, van Krunkelsven L, Herman D, Kint M, Totte E, Shockmel R, Gigot JF: Laparoscopic liver resection of benign liver tumors. Surg Endosc 2003;17:23-30.

$\checkmark 12$ Buell JF, Koffron AJ, Thomas MJ, Rudich S, Abecassis M, Woodle ES: Laparoscopic liver resection. J Am Coll Surg 2005;200:472-480.
13 Buell JF, Thomas MJ, Doty TC, Gersin KS, Merchen TD, Gupta M, Rudich SM, Woodle ES: An initial experience and evolution of laparoscopic hepatic resectional surgery. Surgery 2004;136:804-811.

14 Mala T, Edwin B, Rosseland AR, Gladhaug I, Fosse E, Mathisen O: Laparoscopic liver resection: experience of 53 procedures at a single centre. J Hepatobiliary Pancreat Surg 2005; 12 : 298-303.

15 Kaneko H, Takagi S, Otsuka Y, Tsuchiya M, Tamura A, Katagiri T, Maeda T, Shiba T: Laparoscopic liver resection for hepatocellular carcinoma. Am J Surg 2005; 189:190-194.

16 Tagaki S, Kaneko H, Ishii T, Tamura A, Yamazaki K, Yoshino M, Tsuchiya M, Joubara N, Otuka Y, Shiba T: Laparoscopic hepatectomy for extrahepatic growing tumor. Surgical strategy based on extrahepatic growing index. Surg Endosc 2002;16:1573-1578.

17 Dulucq JL, Wintringer P, Stabilini C, Berticelli J, Mahajna A: Laparoscopic liver resections: a single center experience. Surg Endosc 2005; 19:886-891.

18 Laurent A, Cherqui D, Lesurtel M, Brunetti F, Tayar C, Fagniez PL: Laparoscopic liver resection for subcapsular hepatocellular carcinoma complicating liver disease. Arch Surg 2003; 138:763-769.

19 Mala T, Bohler G, Mathisen O, Bergan A, Soreide $\mathrm{O}$ : Hepatic resection for colorectal metastases: can preoperative scoring predict patient outcome? World J Surg 2002;26:1348-1353.

20 Fong Y, Fortner J, Sun RL, Brennan MF, Blumgart LH: Clinical score for predicting recurrence after hepatic resection for metastatic colorectal cancer: analysis of 1,001 consecutive cases. Ann Surg 1999;230:309-318.

21 Nordlinger B, Guiguet M, Vaillant JC, Balladur P, Boudjema K, Bachellier P, Jaeck D: Surgical resection of colorectal carcinoma metastases to the liver. A prognostic scoring system to improve case selection, based on 1,568 patients. Association Française de Chirurgie. Cancer 1996;77:1254-1262.

22 Petrowsky H, Gonen M, Jarnagin W, Lorenz M, DeMatteo R, Heinrich S, Encke A, Blumgart L, Fong Y: Second liver resections are safe and effective treatment for recurrent hepatic metastases from colorectal cancer: a bi-institutional analysis. Ann Surg 2002;235:863-871.

- 23 Adam R, Pascal G, Azoulay D, Tanaka K, Castaing D, Bismuth H: Liver resection for colorectal metastases: the third hepatectomy. Ann Surg 2003;238:871-883.

24 Edwin B, Mala T, Gladhaug I, Fosse E, Mathisen O, Bergan A, Soreide O: Liver tumors and minimally invasive surgery: a feasibility study. J Laparoendosc Adv Surg Tech A 2001;11: 133-139.

25 Mala T, Edwin B, Gladhaug I, Fosse E, Soreide $\mathrm{O}$, Bergan A, Mathisen O: A comparative study of the short-term outcome following open and laparoscopic liver resection of colorectal metastases. Surg Endosc 2002;16:1059-1063.
26 Intra M, Viani MP, Ballarini C, Pisani Ceretti A, Ongari B, Croce AM, De Murtas G, Marraro G, Spina GP: Gasless laparoscopic resection of hepatocellular carcinoma in cirrhosis. J Laparoendosc Surg 1996;4:263-270.

27 Fong Y, Jarnagin W, Conlon KC, DeMatteo R, Dougherty E, Blumgart LH: Hand-assisted laparoscopic liver resection: lessons from an initial experience. Arch Surg 2000;134:854-859.

-28 Teramoto K, Kawamura T, Takamatsu S, Nakamura N, Kudo A, Noguchi N, Irie T, Arii S: Laparoscopic and thoracoscopic approaches for the treatment of hepatocellular carcinoma. Am J Surg 2005; 189:474-478.

29 Petrowsky H, Demartines N, Rousson V, Clavien PA: Evidence-based value of prophylactic drainage in gastrointestinal surgery: a systematic review and meta-analyses. Ann Surg 2004; 240:1074-1084.

- 30 Azagra JS, Goergen M, Gilbart E, Jacobs D: Laparoscopic anatomical (hepatic) left lateral segmentectomy - technical aspects. Surg Endosc 1996;10:758-761.

- 31 Reich H, McGlynn F, DeCaprio J, Budin R: Laparoscopic excisions of benign liver lesions. Obstet Gynecol 1991;78:956-958.

32 Rogula T, Gagner M: Current status of the laparoscopic approach to liver resection. J Long Term Eff Med Implants 2004; 14:23-31.

33 Gagner M, Rogula T: Laparoscopic liver resection: benefits and controversies. Surg Clin N Am 2004;84:451-462.

34 Cherqui D: Laparoscopic liver resection. Br J Surg 2003;90:644-646.

35 Fujita F, Fujita R, Kanematsu T: New approaches to the minimally invasive treatment of liver cancer. Cancer J 2005;11:52-56.

-36 Hashizume M, Shimada M, Sugimachi K: Laparoscopic hepatectomy: new approach for hepatocellular carcinoma. J Hepatobiliary Pancreat Surg 2000; 7:270-275.

37 Mori T, Abe N, Sugiyama M, Atomi Y: Laparoscopic hepatobiliary and pancreatic surgery: an overview. J Hepatobiliary Pancreat Surg 2002;9:710-722.

38 Berends FJ, Kazemier G, Bonjer HJ, Lange JF: Subcutaneous metastases after laparoscopic colectomy. Lancet 1994;344:58.

39 Zmora O, Gervaz P, Wexner SD: Trocar site recurrence in laparoscopic surgery for colorectal cancer. Surg Endosc 2001;15:788-793.

40 Veldkamp R, Gholghesaei M, Bonjer HJ, Meijer DW, Buunen M, Jeekel J, Anderberg B, Cuesta MA, Cuschierl A, Fingerhut A, Fleshman JW, Guillou PJ, Haglind E, Himpens J, Jacobi CA, Jakimowicz JJ, Koeckerling F, Lacy AM, Lezoche E, Monson JR, Morino M, Neugebauer E, Wexner SD, Whelan RL, European Association of Endoscopic Surgery (EAES): Laparoscopic resection of colon cancer: consensus of the European Association of Endoscopic Surgery (EAES). Surg Endosc 2004;18:1163-1185. 
41 Hansbrough JF, Bender EM, Zapata-Sirvent $\mathrm{R}$, Anderson J: Altered helper and suppressor lymphocyte populations in surgical patients. A measure of postoperative immunosuppression. Am J Surg 1984;148:303-307.

42 Vittimberga FJ Jr, Foley DP, Meyers WC, Callery MP: Laparoscopic surgery and the systemic immune response. Ann Surg 1998;227:326334.

-43 Lacy AM, Garcia-Valdecasas JC, Delgado S, Castells A, Taura P, Pique JM, Visa J: Laparoscopy-assisted colectomy versus open colectomy for treatment of non-metastatic colon cancer: a randomised trial. Lancet 2002;359: 2224-2229.

44 Derouin M, Couture P, Boudreault D, Girard D, Gravel D: Detection of gas embolism by transesophageal echocardiography during laparoscopic cholecystectomy. Anesth Analg 1996;82:119-124.
45 Decailliot F, Cherqui D, Leroux B, Lanteri-Minet M, Ben Said S, Husson E, Duvaldestin P, Stephan F: Effects of portal triad clamping on haemodynamic conditions during laparoscopic liver resection. Br J Anaesth 2001;87:493496.

46 Motson RW: Laparoscopic surgery for colorectal cancer. Br J Surg 2005;92:519-520.

47 Grobmyer SR, Fong Y, D'Angelica M, DeMatteo RP, Blumgart LH, Jarnagin WR: Diagnostic laparoscopy prior to planned hepatic resection for colorectal metastases. Arch Surg 2004; 139:1326-1330.

48 Mala T, Edwin B, Mathisen O, Tillung T, Fosse E, Bergan A, Soreide O, Gladhaug I: Cryoablation of colorectal liver metastases: minimally invasive tumour control. Scand J Gastroenterol 2004;39:571-578.

49 Scaife CL, Curley SA: Complication, local recurrence, and survival rates after radiofrequency ablation for hepatic malignancies. Surg Oncol Clin N Am 2003;12:243-255.
50 DeMatteo RP, Palese C, Jarnagin WR, Sun RL, Blumgart LH, Fong Y: Anatomic segmental hepatic resection is superior to wedge resection as an oncologic operation for colorectal liver metastases. J Gastrointest Surg 2000;4: 178-184.

51 Balli JE, Franklin ME, Almeida JA, Glass JL, Diaz JA, Reymond M: How to prevent portsite metastases in laparoscopic colorectal surgery. Surg Endosc 2000;14:1034-1036.

52 Pawlik TM, Scoggins CR, Zorsi D, Abdalla EK, Eng C, Curley SA, Loyer EM, Muratore A, Mentha G, Capusotti L, Vathey JN: Effect of surgical margin status on survival and site of recurrence after hepatic resection for colorectal metastases. Ann Surg 2005;241:715-724.

53 Scheele J, Altendorf-Hofmann A: Resection of colorectal liver metastases. Langenbecks Arch Surg 1999;384:313-327. 